\title{
Effect of Bagasse Fiber As the Renewable Environmentally Friendly Material on the Properties of the Waterborne Intumescent Fireproof Coating
}

\author{
Wang Zhan \\ Jiangsu University \\ Zhongfei Ma \\ Jiangsu University \\ Zhihao Sun \\ Jiangsu University \\ Lixia Li \\ Jiangsu University \\ Zhaozhan Gu \\ Nanjing University \\ Le Chen ( $\nabla$ chenle26@nju.edu.cn ) \\ Nanjing university \\ Juncheng Jiang \\ Changzhou University \\ Zhiquan Chen \\ Nanjing Tech University
}

\section{Research Article}

Keywords: fireproof, coating, bagasse, renewable

Posted Date: November 8th, 2021

DOI: https://doi.org/10.21203/rs.3.rs-978541/v1

License: (c) (i) This work is licensed under a Creative Commons Attribution 4.0 International License.

Read Full License 


\section{Abstract}

Bagasse was applied as fire-retardant filler to prepare the waterborne intumescent fireproof coating. The effect of bagasse on the properties of the fireproof coating was investigated by fire protection test, thermogravimetric (TG), scanning electron microscope (SEM), energy dispersive spectrometer (EDS), Xray diffraction (XRD), Fourier transform infrared spectroscopy (FTIR), water resistance test and mechanical properties test. The result demonstrated the coating contained $1.5 \mathrm{wt}$.\% bagasse performed best in fire protection, thermal stability, oxidation resistance. Moreover, the char layer was dense and continuous. However, the fireproof coating contained $2 \mathrm{wt}$ \% bagasse had excellent performance in water resistance test and mechanical properties test due to its properties of fiber. In addition, the components and chemical structure of char layer were characterized to study the flame retardant mechanism of bagasse in the fireproof coating.

\section{Introduction}

With the rapid development of construction industry, steel structure is mainly used in the high-rise building and petrochemical enterprises [1-3]. However, fire has always been the potentially huge threat to the steel structure $[4,5]$. When the fire occurs, the temperature of fire situation is in excess of $500^{\circ} \mathrm{C}$ in the short time [6, 7]. In this case, the steel structure will lose the strength and integrity because of the high conductivity [8]. As an effective passive measure, fireproof coating is applied to protect the steel structure, pipes and storage tank from the fire [9-12]. Generally, fireproof coating is mainly composed of polymer binders, acid source, carbon source, blowing agent, filler and promoter [13]. According to the previous reports, fire-retardant filler has an important influence on the properties of the fireproof coating, such as fire protection, thermal stability, water resistance and so on. A variety of fire-retardant fillers have been applied to enhance the properties of the fireproof coating [14-17]. However, some fire-retardant fillers are not only expensive, but also pollute the environment in the production process. Therefore, the environmentally friendly fire-retardant filler was demanded to satisfy fire protection and environmental protection.

Bagasse is recognized as the typical representative for biomass fibrous residue [18]. As the nature plant fiber, bagasse is composed of cellulose, hemicellulose and lignin [19]. Based on the statistical data, large quantities of bagasse were produced every year. Moreover, bagasse has many peculiarities, such as renewability, tenacious, biocompatibility and environmental friendliness. According to the previous reports, bagasse was used to enhance the mechanical strength, aging resistance etc [20].

Hemmati et al. used the counterrotating twin screw extruder to produce bagasse/polypropylene composites and studied the fire resistance, durability and biological properties [21]. Chen et al. used layerby-layer assembly to prepare an environmentally benign flame retardant for epoxy resin (EP) to decrease the peak heat release rate and total heat release [22]. Griffin studied the influences of ammonium sulphate, boric acid and borax on the mass-loss rate and combustion characteristics of sugar-cane bagasse [23]. The result showed the bagasse treated by chemicals could reduce flammability risk. Han et 
al. used bagasse fiber to make flame retarding composites (BFRCs) and the BFRCs performed good water resistance and flame retardant. The index of flame spread was 13.6 and the smoke index was 108, reaching Class A of the ASTM E84-08 Standard [24]. At present, bagasse has been applied in various composites for building, vehicles, waste minimization etc [25].

The application of bagasse in the fireproof coating is a new mean for rational recycling of bagasse. In view of this, the fireproof coating contained the bagasse was subjected to a series of tests. The fire protection and thermal stability of the fireproof coatings was conducted by the fire protection test and $\mathrm{TG} / \mathrm{DSC}$, respectively. After the fire protection test, the microstructure and elemental component of char layer were characterized by scanning electronic microscopy (SEM), energy dispersive (EDS), Fourier transform infrared (FTIR), X-ray diffraction (XRD). Moreover, mechanical properties and water resistance were discussed. Based on the data, the effect of the bagasse on the fireproof coatings was evaluated.

\section{Experimental}

\subsection{Materials and methods}

Acrylic resin emulsion was provided by Shandong Jingyuan Technology Co., Ltd and used as matrix material. Ammonium polyphosphate (APP), Dipentaerythritol (DPER), Titanium dioxide $\left(\mathrm{TiO}_{2}\right)$ were provided by Aladdin Industrial Co., Ltd. Melamine (MEL) was supplied by Shanghai Lingfeng chemical reagent Co., Ltd. The bagasse was bought from fruit shop. The deionized water was homemade in laboratory.

\subsection{Preparation of bagasse powder}

Firstly, the squeezed bagasse was soaked into water bath pot at the temperature of $85^{\circ} \mathrm{C}$ for $24 \mathrm{~h}$ to remove the sugar residue and impurities. Secondly, the bagasse was dried in the high temperature oven at $35^{\circ} \mathrm{C}$ for $12 \mathrm{~h}$. Finally, the bagasse was made into powder by disintegrator. Fig. 1 shows the macrograph (Fig. 1a) and the scanning electron microscopy image (Fig. 1b d) of the bagasse powder.

\subsection{Preparation of fireproof coating}

The compositions of the fireproof coating are listed in Table 1. The APP, DPER, MEL, bagasse powder, $\mathrm{TiO}_{2}$ and deionized water were mixed with the speed stirring of $1500 \mathrm{r} / \mathrm{min}$ for $25 \mathrm{~min}$. Acrylic resin emulsion and promoters were added with the speed stirring of $500 \mathrm{r} / \mathrm{min}$ for $25 \mathrm{~min}$. The fireproof coating was coated on the Q235 steel plate $(100 \mathrm{~mm} \times 100 \mathrm{~mm} \times 2 \mathrm{~mm})$ and the samples were cured at room temperature for 7 days. 
Table 1

Formulations of fireproof coatings

\begin{tabular}{|llllll|}
\hline Component (wt.\%) & SP-0 & SP-1 & SP-2 & SP-3 & SP-4 \\
\hline Emulsion & 25 & 25 & 25 & 25 & 25 \\
\hline APP/ DPER/MEL & $20 / 10 / 10$ & $20 / 10 / 10$ & $20 / 10 / 10$ & $20 / 10 / 10$ & $20 / 10 / 10$ \\
\hline $\mathrm{TiO}_{2}$ & 5 & 5 & 5 & 5 & 5 \\
\hline bagasse & 0 & 0.5 & 1 & 1.5 & 2 \\
\hline promoter & 2 & 2 & 2 & 2 & 2 \\
\hline deionized water & 28 & 27.5 & 27 & 26.5 & 26 \\
\hline
\end{tabular}

\subsection{Characterization of coating}

The homemade experimental device of fire protection test is shown in Fig. 2. According to the backside temperature of steel plate to evaluate the fire protection of the fireproof coatings. Moreover, the intumescent factor $(N)$ of the char layer was calculated according to the following equation:

$$
N=\frac{d_{2}-d_{0}}{d_{1}-d_{0}}
$$

1

Where $d_{0}$ was the thickness of the steel plate, $d_{1}$ was the thickness of the sample before the test and $d_{2}$ was the thickness of the sample after the test.

The sample of fireproof coating was ground to powder and screened. The thermal stability of the fireproof coating was analyzed by thermogravimetric analysis (TG-DSC NETZSCH STA 449F3) under $\mathrm{N}_{2}$ atmosphere from the room temperature to $800^{\circ} \mathrm{C}$.

Morphology of char layer after fire protection test was examined and analyzed by S-3400N II (Hitachi Co., Japan) with an accelerating voltage of $20 \mathrm{kV}$. The elemental composition of the char layer was recorded by EDS.

FTIR spectra was performed on NEXUS870 FTIR spectrometer (NICOLET Co., America) to study the chemical structure of the char layer at the scanning range of $4000 \mathrm{~cm}^{-1}$ to $400 \mathrm{~cm}^{-1}$. XRD was used to investigate the different compounds in the residual carbon by monitoring those diffractions that appeared from $15^{\circ}$ to $75^{\circ}$.

Water resistance test was conducted to evaluate the water resistance of the fireproof coating. Two thirds of the sample was immersed in the water at room temperature for $1 \mathrm{~h}$ during the test and weighed after drying at $25^{\circ} \mathrm{C}$ for $6 \mathrm{~h}$. 


$$
\mathrm{I}=\frac{m_{2}-m_{1}}{m_{1}}
$$

2

Where $m_{1}$ was the weight of the coating before the water resistance test, $m_{2}$ was the weight of the coating after the water resistance test.

In the mechanical properties test, falling-ball impact tester was used according to GB/T 1732-93. The impact resistance of the coating was evaluated according to the crack degree on the surface of the coating.

\section{Results And Discussion 3.1 Fire protection test}

The curves and data of the backside temperature of the samples during the fire protection test were shown in Fig. 3 and Table 2. Based on the curves, the backside temperature increased rapidly within the first $10 \mathrm{~min}$ and the backside temperature of the samples was $356.6^{\circ} \mathrm{C}, 277.7^{\circ} \mathrm{C}, 243.0^{\circ} \mathrm{C}, 201.2^{\circ} \mathrm{C}$, $222.5^{\circ} \mathrm{C}$, respectively. After the fire protection test, the backside temperature reached to the equilibrium temperature and the final backside temperature was $397^{\circ} \mathrm{C}, 322.1^{\circ} \mathrm{C}, 283.9^{\circ} \mathrm{C}, 229.0^{\circ} \mathrm{C}, 264.3^{\circ} \mathrm{C}$, respectively. The result demonstrated that the bagasse enhanced fire protection of the fireproof coatings. However, more addition of the bagasse would lead to the decreasing of fire protection.

Table 2

The data ot the backside temperature

\begin{tabular}{|llllll|}
\hline Sample & SP-0 & SP-1 & SP-2 & SP-3 & SP-4 \\
\hline $10 \min \left({ }^{\circ} \mathrm{C}\right)$ & 356.6 & 277.7 & 243.0 & 201.2 & 222.5 \\
\hline $15 \min \left({ }^{\circ} \mathrm{C}\right)$ & 364.5 & 292.2 & 269.2 & 217.5 & 244.1 \\
\hline $30 \min \left({ }^{\circ} \mathrm{C}\right)$ & 397.0 & 322.1 & 283.9 & 229.0 & 264.3 \\
\hline
\end{tabular}

The images of samples before the fire protection test were shown in Fig. 4. It can be clearly observed that the surface of the samples became rougher with the increasing content of bagasse. This is because of the bagasse is composed of cellulose, hemicellulose and lignin. Thus, the addition of bagasse would make the surface of the samples became rough. After the fire protection test, the images of char layers were shown in Fig. 5. In Fig. 5a and 5b, many cracks could be observed. In addition, some areas of the char layer collapsed. These were disadvantageous to fire insulation, resulting in poor fire protection. With the addition amount of bagasse increased, the number and size of cracks of the char layer reduced in Fig. 5c 5e However, the central area in Fig. 5c collapsed and the crack in Fig. 5e had the trend of increasing. Although some cracks still could be observed in Fig. $5 d$, the surface of the char layer was relatively complete. 
The height and expansion rate of char layers were shown in Fig. 6. The height of char layers was 7.86 $\mathrm{mm}, 8.82 \mathrm{~mm}, 8.96 \mathrm{~mm}, 10.62 \mathrm{~mm}, 9.38 \mathrm{~mm}$, respectively. After calculation, the corresponding expansion rate of char layers was $2.93,3.41,3.48,4.31,3.69$. Based on the data of char layer, the char layer of SP-3 exhibited excellent expansion performance. According to the previous studies, the fireproof coatings with high expansion have excellent fire protection [26, 27].

In combination with backside temperature and information of char layer, bagasse has a positive effect on fire protection and the SP-3 performed best in the fire protection. These are attributed to the excellent expansion performance of bagasse, leading to greatly beneficial to fire protection. However, excessive addition of bagasse would lead to cracking of the char layer, resulting in decreasing the fire protection.

In summary, the possible fire-retardant mechanism of fireproof coating was shown in Fig. 7. When the fireproof coating suffered the heat, APP reacted with DPER and form the char structure. During the progress, the bagasse occurred carbonization and promoted the carbonization reaction. MEL decomposed and produced gases, leading to the expansion of the char layer [28]. The char layer could prevent the transferring of the heat and oxygen [29]. Besides, the carbonization bagasse formed the "tortuous path", leading to the heat wasting more time to reach the steel structure [30]. With the content of the bagasse increased, the effect is more significant. However, excessive content of the bagasse would lead to crack and collapse of the char layer, thus resulting in poor fire protection.

\subsection{Thermal behavior of bagasse and fireproof coating}

The TG/DSC curves of bagasse was shown in Fig. 8. Because of the release of moisture, the bagasse powder has $5 \%$ weight loss before $100^{\circ} \mathrm{C}$ [31]. There was obvious weight loss between $200^{\circ} \mathrm{C}$ and $400^{\circ} \mathrm{C}$ and the significant exothermic peak occurred during $300^{\circ} \mathrm{C} \sim 400^{\circ} \mathrm{C}$. This can be ascribed to depolymerization and pyrolysis of the bagasse [32]. The TG curves of fireproof coatings were shown in Fig. 9. The residual weight of the fireproof coatings was $39.89 \%, 40.35 \%, 40.80 \%, 53.19 \%, 43.11 \%$, respectively. The result showed the thermal stability of fireproof coating was reinforced by the bagasse. Especially, the fireproof coating adding $1.5 \mathrm{wt} . \%$ had the best thermal stability. However, adding high content of bagasse caused the cracking of the char layer, leading to the decomposition of internal flame retardant system of the fireproof coating.

\subsection{Morphology of the coatings and char layers}

The SEM images of cross section of fireproof coatings were shown in Fig. 10. The cross section of the fireproof coating without the bagasse was osteoporosis and some hole areas were observed. With the addition of the bagasse, the internal area of the coatings became dense, which was considered as a good isolation layer to prevent the heat reaching the surface of the protected substance. 
The dense foam internal structure of the char layer has excellent effect of fire protection [33]. The SEM images of the char layer were shown in Fig. 11. The internal structure of char layer in Fig. 11a exhibited relatively discontinuous, thus the heat and oxygen could transfer to the steel plate easily. The char layer in Fig. 11b and Fig. 11c became continuous, but some small pores still could be observed. The bagasse formed protective barrier and prevented the transferring of heat. Moreover, the bagasse could enhance the mechanical properties of the char layer and prevent the formation of cracks. The internal structure in Fig. $11 \mathrm{~d}$ and Fig. $11 \mathrm{e}$ was dense without obvious pores, resulting in better fire protection. However, the excessive bagasse had a negative effect on the fireproof coating and led to excessive inflation, resulting in the formation of cracks. The internal structure in Fig. 11d was denser than in Fig. 11e, which caused the SP-3 has better fire protection.

\subsection{Element analysis of intumescent char layers}

EDS was carried out to investigate the element compositions of the char layer. Carbon content in char layer indicated the degree of carbonized, and oxygen content indicated the oxidation degree of the coating [34]. High carbon content means that the fireproof coating has better oxidation resistance. The element composition of the char layers after the fire protection test is shown in Table 3. The carbon content of the char layer is $16.15 \%, 27.18 \%, 29.68 \%, 35.52 \%, 30.40 \%$ and the oxygen content is $49.96 \%$, $46.90 \%, 44.25 \%, 42.48,44.56 \%$, respectively.

Based on the date of element compositions, the result demonstrated that the carbon content increased within $0.5 \mathrm{wt} . \% \sim 1.5 \mathrm{wt} . \%$ of the bagasse. When the adding content of bagasse reached $2 \mathrm{wt} . \%$, excessive expansion of bagasse caused the formation of the cracks, leading to accelerating decomposition of char layer and decreasing the carbon content.

Table 3

Element composition of the char layers

\begin{tabular}{|lllll|}
\hline Sample & \multicolumn{4}{l|}{ Element composition (\%) } \\
\cline { 2 - 5 } & C & O & P & Ti \\
\hline SP-0 & 16.15 & 49.96 & 19.83 & 14.06 \\
\hline SP-1 & 27.18 & 46.90 & 15.04 & 10.88 \\
\hline SP-2 & 29.68 & 44.25 & 15.41 & 10.66 \\
\hline SP-3 & 35.52 & 42.48 & 13.59 & 8.41 \\
\hline SP-4 & 30.40 & 44.56 & 16.02 & 9.02 \\
\hline
\end{tabular}

\subsection{XRD and FTIR of char layers}


To better understand the composition and structure, bagasse and char layers were characterized by XRD and FTIR, respectively. The FTIR of the bagasse is shown in Fig. 12. There are obvious absorption peaks at $3392 \mathrm{~cm}^{-1}, 2913 \mathrm{~cm}^{-1}, 1732 \mathrm{~cm}^{-1}, 1605 \mathrm{~cm}^{-1}, 1515 \mathrm{~cm}^{-1}, 1428 \mathrm{~cm}^{-1}, 1374 \mathrm{~cm}^{-1}, 1244 \mathrm{~cm}^{-1}, 1051 \mathrm{~cm}^{-1}$, $908 \mathrm{~cm}^{-1}, 867 \mathrm{~cm}^{-1}$ and $560 \mathrm{~cm}^{-1}$. The absorption peak at $3392 \mathrm{~cm}^{-1}$ is the stretching vibration absorption peak of $\mathrm{O}-\mathrm{H}$ on carbohydrates, due to the formation of intermolecular and intramolecular hydrogen bonds [35]. The absorption peak at $2913 \mathrm{~cm}^{-1}$ is $\mathrm{C}-\mathrm{H}$ stretching vibration. The $\mathrm{C}=\mathrm{O}$ stretching vibration of carboxyl group in saturated fatty acids of bagasse is observed at $1732 \mathrm{~cm}^{-1}$. The absorption peak at $1605 \mathrm{~cm}^{-1}$ and $1515 \mathrm{~cm}^{-1}$ are the stretching vibration peaks of $\mathrm{C}=\mathrm{C}$ in aromatic compounds and the skeleton vibration peaks of aromatic rings. The absorption peaks at $1428 \mathrm{~cm}^{-1}$ and $1374 \mathrm{~cm}^{-1}$ are $\mathrm{C}-\mathrm{H}$ deformation vibration. The $\mathrm{C}-\mathrm{O}$ stretching vibration peak on the aromatic ring of lignin is at $1244 \mathrm{~cm}^{-1}$. At $1051 \mathrm{~cm}^{-1}$ is the stretching vibration of C-O-C. The absorption peaks at $908 \mathrm{~cm}^{-1}, 867 \mathrm{~cm}^{-1}$ and $560 \mathrm{~cm}^{-1}$ in the low frequency region are all caused by $\mathrm{C}-\mathrm{H}$ out-of-plane deformation vibration and bending vibration. The characteristic absorption peaks above are caused by the typical characteristic structure of bagasse.

The FTIR of the char layers is shown in Fig. 13. The wider absorption peak at $3010 \mathrm{~cm}^{-1}$ is the $-\mathrm{OH}$ stretching vibration of water absorbed by the char layer [36]. The absorption peak at $1616 \mathrm{~cm}^{-1}$ is the stretching vibration of $C=C$. The absorption peaks at $1082 \mathrm{~cm}^{-1}$ and $957 \mathrm{~cm}^{-1}$ may be caused by the antisymmetric stretching vibration of $\mathrm{P}-\mathrm{O}-\mathrm{C}$ and the stretching vibration of $\mathrm{P}-\mathrm{O}-\mathrm{Ti}$. The absorption peaks at $742 \mathrm{~cm}^{-1}, 620 \mathrm{~cm}^{-1}$ and $563 \mathrm{~cm}^{-1}$ are caused by the vibration of Ti-O, indicating the existence of $-\mathrm{OH}, \mathrm{N}-\mathrm{H}$, $\mathrm{C}-\mathrm{H}$ and $\mathrm{C}=\mathrm{C}$ structure of carbonized substances after thermal decomposition of fireproof coatings, and the existence of $\mathrm{Ti}, \mathrm{P}$ and inorganic salts, etc.

After the fire protection test, white inorganic materials were observed in the char layer. XRD spectra of the char layer was shown in Fig. 14. The significant XRD peaks are characterized as titanium dioxide $\left(\mathrm{TiO}_{2}\right)$ and titanium pyrophosphate $\left(\mathrm{TiP}_{2} \mathrm{O}_{7}\right)$, respectively [37]. The results showed that $\mathrm{TiO}_{2}$ reacted with APP and $\mathrm{TiP}_{2} \mathrm{O}_{7}$ was generated during the combustion. According to the previous research, these inorganic materials had an obvious heat insolation effect [38-40].

\subsection{Water resistance test}

The fireproof coating applying in outdoor often suffers from the erosion of rain, leading to the desquamation of the coating [41, 42]. In this case, the fire protection of the fireproof coating will decrease. Therefore, the water resistance of fireproof coating is very important. The images of the fireproof coatings immersed for 1 hour were shown in Fig. 15. Some blisters were observed on the surface of the fireproof coating in Fig. 15a. However, noticeable change was observed in Fig. 15b 15d.

The weight loss percentage of the fireproof coating with the immersion time is shown in Fig. 16. During the water resistance test, the hydrophilic flame-retardants (APP, DPER and MEL) migrated from the 
coating to the water, thus resulting in the weight loss of the coating. At the same time, water and corrosive ions $\left(\mathrm{OH}^{-}, \mathrm{H}^{+}\right)$infiltrated into the coating, leading to the weight increased [43]. After the water resistance test, the weight loss of the fireproof coating was $11.7 \%, 10.3 \%, 9.5 \%, 8.3 \%, 4.94 \%$. The water resistance of the coating increased with the addition of the bagasse. This is because the bagasse formed multilayer structure to block the water and slow down the migration of flame-retardants.

\subsection{Mechanical properties test}

Mechanical properties test is also an important performance of fireproof coating. The images of the fireproof coating after the mechanical properties test were shown in Fig. 17. Obvious cracks were observed on the surface of the coating in Fig. 17a. A significant increase in the impact resistance when the fireproof coating was loaded with bagasse. With the addition of bagasse increased in Fig. 17b 17d, the size of cracks on coating decreased. Especially in Fig. 17e, there was no cracks on the surface of the coating. The fireproof coating with $2 \mathrm{wt}$.\% of bagasse performed best impact resistance. This interfacial separation of matrix and fibers of the bagasse absorbed more impact energy, resulting the coating performing great impact resistance $[44,45]$.

\section{Conclusions}

In this study, the bagasse was used as fire-retardant filler to prepare the fireproof coating. The fire protection, TG, SEM, EDS, XRD, FTIR, water resistance and mechanical properties were conducted to investigate the effect of bagasse on the fireproof coating. The result demonstrated the backside temperature of the fireproof coating with $1.5 \mathrm{wt} \%$ bagasse decreased the backside temperature from $356.6^{\circ} \mathrm{C}$ to $201.2^{\circ} \mathrm{C}$ and the residual weight reached $53.19 \%$. Moreover, the char layer of this sample was dense and carbon content reached $35.52 \%$, which demonstrated better oxidation resistance of the coating. The result of XRD and FTIR exhibited the chemical composition of the char layer. Moreover, titanium pyrophosphate was observed due to reaction of titanium dioxide with ammonium polyphosphate. Because of the special fiber structure, the bagasse enhanced the water resistance and mechanical properties of the coating. In particular, the fireproof coating with $2 \mathrm{wt} . \%$ had better performance and only had $4.94 \%$ weight loss in the water resistance test. and reduce the cracks on the surface of the fireproof coating. Based on the experimental data, this study demonstrated a new means of recycling the bagasse and provided engineering guidance for the application of environmental protection fire retardant filler.

\section{Declarations}

Acknowledgement 
The authors are grateful for the support given by key project of National Natural Science Foundation of China under Grant No.21436006, and key project of National Natural Science Foundation of Chinaunder Grant No.51834007.

\section{Data Availability}

Due to the nature of this research, participants of this study did not agree for their data to be shared publicly, so supporting data is not available.

\section{References}

[1] Gardelle B, Duquesne S, Vandereecken P, Bellayer S, Bourbigot S. Resistance to fire of intumescent silicone based coating: The role of organoclay. PROG ORG COAT. 2013;76(11):1633-41.http://d oi.org/10.1016/j.porgcoat.2013.07.011.

[2] Liu Z, Dai M, Wang C, Zhang Q, Zhang Y, Jin B, et al. Effects of the addition mode and amount of organic montmorillonite in soft-core/hard-shell emulsion on fire protection, water resistance and stability of fire retardant coating. PROG ORG COAT. 2016;101:350-8.http://doi.org/10.1016/j.porgcoat.20 16.09.001.

[3] Dong Y, Wang G, Su Q. Influence of nano-boron nitride on anti-aging property of waterborne fireresistive coatings. J COAT TECHNOL RES. 2014;11(5):805-15. http://d oi.org/10.1007/s11998-013-95387.

[4] Yu J, Wu S, Yu Y, Chen H, Fan H, Liu J, et al. Process system failure evaluation method based on a Noisy-OR gate intuitionistic fuzzy Bayesian network in an uncertain environment. PROCESS SAF ENVIRON. 2021;150:281-97.http://doi.org/10.1016/j.pse p.2021.04.024.

[5] Benson C, Argyropoulos CD, Dimopoulos C, Mikellidou CV, Boustras G. Safety and risk analysis in digitalized process operations warning of possible deviating conditions in the process environment. PROCESS SAF ENVIRON. 2021;149:750-7.http://doi.org/10.1016/j.psep.2021.02.039.

[6] Xue Y, Zhang S, Yang W. Influence of expanded vermiculite on fire protection of intumescent fireproof coatings for steel structures. J COAT TECHNOL RES. 2015;12(2):357-64.http://doi.org/10.1007/s11998014-9626-3.

[7] Yew MC, Ramli Sulong NH, Yew MK, Amalina MA, Johan MR. Eggshells: A novel bio-filler for intumescent flame-retardant coatings. PROG ORG COAT. 2015;81:116-24.http://doi.org/10.1016/j.por gcoat.2015.01.003.

[8] Rhys JA. Intumescent coatings and their uses. FIRE MATER. 1980 1980-01-01;4(3):154-6.http://do i.org/10.1002/fam.810040308. 
[9] Puri RG, Khanna AS. Intumescent coatings: A review on recent progress. J COAT TECHNOL RES. 2017;14(1):1-20.http://doi.org/10.1007/s11998-016-9815-3.

[10] Alongi J, Han Z, Bourbigot S. Intumescence: Tradition versus novelty. A comprehensive review. PROG POLYM SCI. 2015;51:28-73.http://doi.org/10.1016/j.progpolymsci.2015.04.010.

[11] Roberts TA, Shirvill LC, Waterton K, Buckland I. Fire resistance of passive fire protection coatings after long-term weathering. PROCESS SAF ENVIRON. 2010;88(1):1-

19.http://doi.org/10.1016/j.psep.2009.09.003.

[12] Ramsden N, Abusaieda KAM. A study of water cooling using different water application techniques to protect storage tank walls against thermal radiation. PROCESS SAF ENVIRON. 2017;109:577-98.

[13] Duquesne S, Magnet S, Jama C, Delobel R. Intumescent paints: fire protective coatings for metallic substrates. Surface and Coatings Technology. 2004;180-181:302-

7.http://doi.org/10.1016/j.psep.2017.04.009.

[14] Yew MC, Ramli Sulong NH, Yew MK, Amalina MA, Johan MR. Influences of flame-retardant fillers on fire protection and mechanical properties of intumescent coatings. PROG ORG COAT. 2015;78: 5966.http://doi.org/10.1016/j.porgcoat.2014.10.006.

[15] Xu W, Wang X, Wu Y, Li W, Chen C. Functionalized graphene with Co-ZIF adsorbed borate ions as an effective flame retardant and smoke suppression agent for epoxy resin. J HAZARD MATER. 2019;363:138-51.http://doi.org/10.1016/j.jhazmat.2018.09.086.

[16] Fan F, Xia Z, Li Q, Li Z. Effects of inorganic fillers on the shear viscosity and fire retardant performance of waterborne intumescent coatings. PROG ORG COAT. 2013;76(5):84451.http://doi.org/10.1016/j.porgcoat.2013.02.002.

[17] Zhan W, Gu Z, Jiang J, Chen L. Influences of surface area of graphene on fire protection of waterborne intumescent fire resistive coating. PROCESS SAF ENVIRON. 2020;139:106-13. http://doi.org/10.1016/j.psep.2020.04.004.

[18] Oliveira TA, Oliveira Mota I, Mousinho FEP, Barbosa R, Carvalho LH, Alves TS. Biodegradation of mulch films from poly (butylene adipate co-terephthalate), carnauba wax, and sugarcane residue. J APPL POLYM SCI. 2019 2019-01-01;136(47):48240.http://doi.org/10.1002/app.48240.

[19] Satyanarayana KG, Guimarães JL, Wypych F. Studies on lignocellulosic fibers of Brazil. Part I: Source, production, morphology, properties and applications. Composites Part A: Applied Science and Manufacturing. 2007;38(7):1694-709.http://doi.org/10.1016/j.compositesa.2007. 0 2.006.

[20] Amir N, Abd. Majid AA, Ahmad F. Effects of Hybrid Fibre Reinforcement on Fire Resistance Performance and Char Morphology of Intumescent Coating. MATEC Web of Conferences. 2016;38:3001. http://doi.org/10.1051/matecconf/20163803001. 
[21] Hemmati F, Garmabi H. A study on fire retardancy and durability performance of bagasse fiber/polypropylene composite for outdoor applications. J THERMOPLAST COMPOS. 2013;26(8):104156.http://doi.org/10.1177/0892705711433350.

[22] Chen Z, Jiang J, Yu Y, Chen G, Chen T, Zhang Q. Layer-by-layer assembled bagasse to enhance the fire safety of epoxy resin: A renewable environmental friendly flame retardant. J APPL POLYM SCI. 2021 2021-03-15;138(11):50032.http://doi.org/10.1002/app.50032.

[23] Griffin GJ. The effect of fire retardants on combustion and pyrolysis of sugar-cane bagasse. BIORESOURCE TECHNOL. 2011;102(17):8199-204.http://doi.org/10.1016/j.biortech.2011.05.051.

[24] Wenjia Han AKCA. UTILIZATION OF BAGASSE FIBER FOR PREPARATION OF BIODEGRADABLE FLAME RETARDING COMPOSITES (BFRCS). Bioresources. 2010;3(5):1605-

17.http://doi.org/10.1007/s00226-009-0268-z.

[25] JOHN M, THOMAS S. Biofibres and biocomposites. CARBOHYD POLYM. 2008;2008-02-08;71(3):34364.http://doi.org/10.1016/j.carbpol.2007.05.040.

[26] Zhan W, Chen L, Cui F, Gu Z, Jiang J. Effects of carbon materials on fire protection and smoke suppression of waterborne intumescent coating. PROG ORG COAT. 2020;140:105491.http://doi.org/10.1016/j.porgcoat.2019.105491.

[27] Nørgaard KP, Dam-Johansen K, Català P, Kiil S. Investigation of char strength and expansion properties of an intumescent coating exposed to rapid heating rates. PROG ORG COAT. 2013;76(12):18517.http://doi.org/10.1016/j.porgcoat.2013.05.028.

[28] Ullah S, Ahmad F, Shariff AM, Bustam MA, Gonfa G, Gillani QF. Effects of ammonium polyphosphate and boric acid on the thermal degradation of an intumescent fire retardant coating. PROG ORG COAT. 2017;109:70-82.http://doi.org/10.1016/j.porgcoat.2017.04.017.

[29] Jimenez M, Duquesne S, Bourbigot S. Kinetic analysis of the thermal degradation of an epoxy-based intumescent coating. POLYM DEGRAD STABIL. 2009;94(3):404-9.http://do i.org/10.1016/j.polymdegradstab.2008.11.021.

[30] Wang X, Kalali EN, Wan J, Wang D. Carbon-family materials for flame retardant polymeric materials. PROG POLYM SCl. 2017;69:22-46.http://doi.org/10.1016/j.progpolymsci.2017.02.001.

[31] Margem FM, Martins LBDS, Rosa NCG, Monteiro SN. Thermal Behavior of Banana Fiber: Characterization of Minerals, Metals, and Materials 2012.

[32] Moubarik A, Grimi N, Boussetta N. Structural and thermal characterization of Moroccan sugar cane bagasse cellulose fibers and their applications as a reinforcing agent in low density polyethylene. Composites Part B: Engineering. 2013;52:233-8.http://doi.org/10.1016/j.compositesb.2013.0 4.040. 
[33] Puri RG, Khanna AS. Effect of cenospheres on the char formation and fire protective performance of water-based intumescent coatings on structural steel. PROG ORG COAT. 2016;92:8-

15.http://doi.org/10.1016/j.porgcoat.2015.11.016.

[34] Zhan W, Chen L, Gu Z, Jiang J. Influence of graphene on fire protection of intumescent fire retardant coating for steel structure. Energy Reports. 2020;6:693-7.http://doi.org/10.1016/j.egyr.201 9.11.139.

[35] Horikawa Y, Sugiyama J. Accessibility and size of Valonia cellulose microfibril studied by combined deuteration/rehydrogenation and FTIR technique. CELLULOSE. 2008;15(3):419-24.htt p://doi.org/10.1007/s10570-007-9187-z.

[36] Wang N, Zhang M, Kang P, Zhang J, Fang Q, Li W. Synergistic Effect of Graphene Oxide and Mesoporous Structure on Flame Retardancy of Nature Rubber/IFR Composites. MATERIALS. 2018 201806-13;11(6):1005. http://do i.org/10.3390/ma11061005.

[37] Aziz H, Ahmad F. Effects from nano-titanium oxide on the thermal resistance of an intumescent fire retardant coating for structural applications. PROG ORG COAT. 2016;101:4319.http://doi.org/10.1016/j.porgcoat.2016.09.017.

[38] Wang Z, Han E, Ke W. Influence of expandable graphite on fire resistance and water resistance of flame-retardant coatings. CORROS SCI. 2007;49(5):2237-53.http://doi.org/10.1016/j.cor sci.2006.10.024.

[39] Dhineshbabu NR, Arunmetha S, Manivasakan P, Karunakaran G, Rajendran V. Enhanced functional properties of cotton fabrics using $\mathrm{TiO}_{2} / \mathrm{SiO}_{2}$ nanocomposites. J IND TEXT. 2014;45(5):67492.http://doi.org/10.1177/1528083714538684.

[40] Li H, Hu Z, Zhang S, Gu X, Wang H, Jiang P, et al. Effects of titanium dioxide on the flammability and char formation of water-based coatings containing intumescent flame retardants. PROG ORG COAT. 2015;78:318-24.http://doi.org/10.1016/j.porgcoat.2014.08.003.

[41] Cheng L, Liu C, Han D, Ma S, Guo W, Cai H, et al. Effect of graphene on corrosion resistance of waterborne inorganic zinc-rich coatings. J ALLOY COMPD. 2019;774:255-64.http://doi.org/ 10.1016/j.jallcom.2018.09.315.

[42] Quezada-Rentería JA, Cházaro-Ruiz LF, Rangel-Mendez JR. Synthesis of reduced graphene oxide (rGO) films onto carbon steel by cathodic electrophoretic deposition: Anticorrosive coating. CARBON. 2017;122:266-75.http://doi.org/10.1016/j.carbon.2017.06.074.

[43] Wang J, Wang G. Influences of montmorillonite on fire protection, water and corrosion resistance of waterborne intumescent fire retardant coating for steel structure. Surface and Coatings Technology. 2014;239:177-84.http://doi.org/10.1016/j.surfcoat.2013.11.037. 
[44] Jacob M, Joseph S, Pothan LA, Thomas S. A study of advances in characterization of interfaces and fiber surfaces in lignocellulosic fiber-reinforced composites. COMPOS INTERFACE. 2005 2005-01-01;12(12):95-124.http://doi.org/10.1163/1568554053542115.

[45] Faruk O, Bledzki AK, Fink H, Sain M. Progress Report on Natural Fiber Reinforced Composites. MACROMOL MATER ENG. 2014;299(1):9-26.http://doi.org/10.1002/mam e .201300008.

\section{Figures}
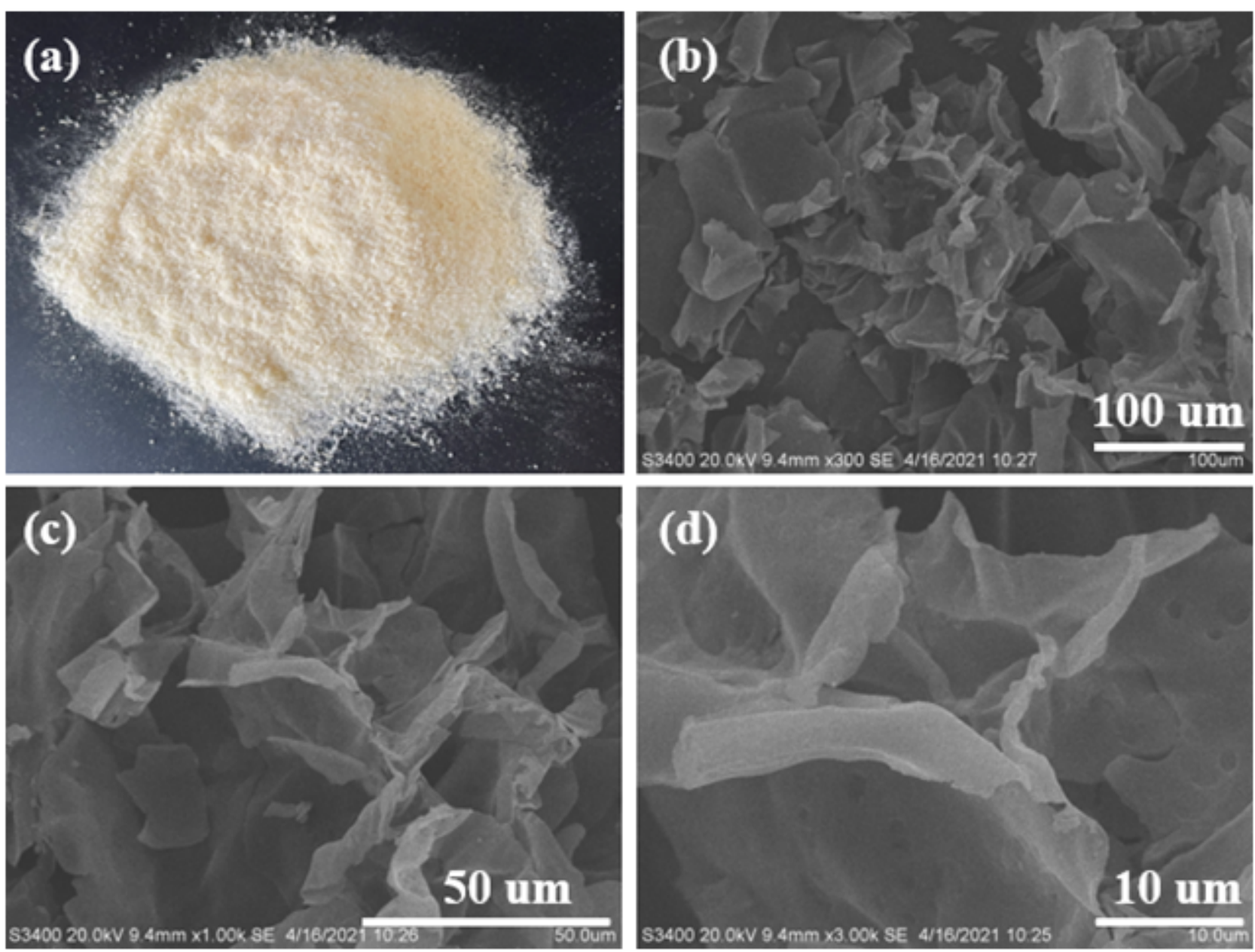

\section{Figure 1}

The macrograph and the scanning electron microscopy image of the bagasse powder. (a) bagasse powder, (b) (c) (d) scanning electron microscopy image of the bagasse powder 


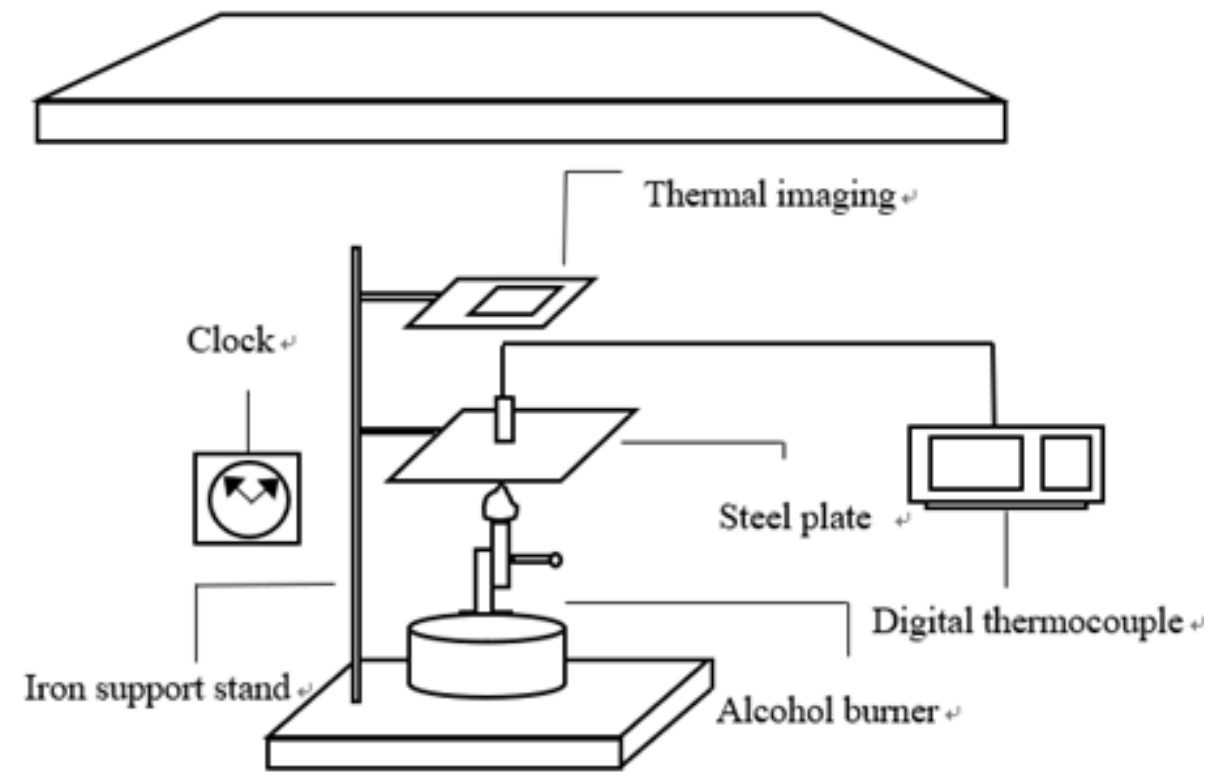

Figure 2

Equipment of fire protection test

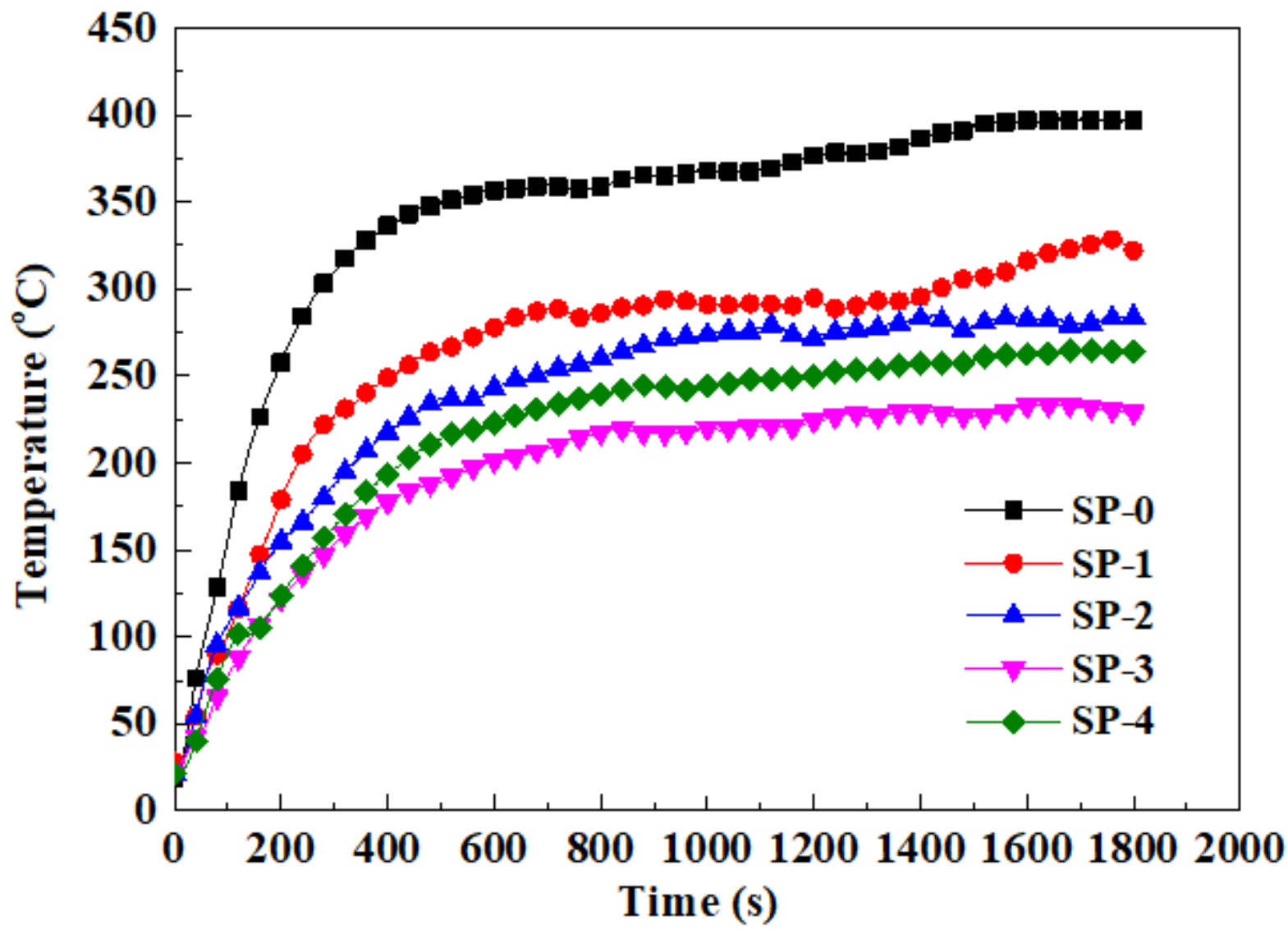

Figure 3

The curves of backside temperature during the fire protection test 


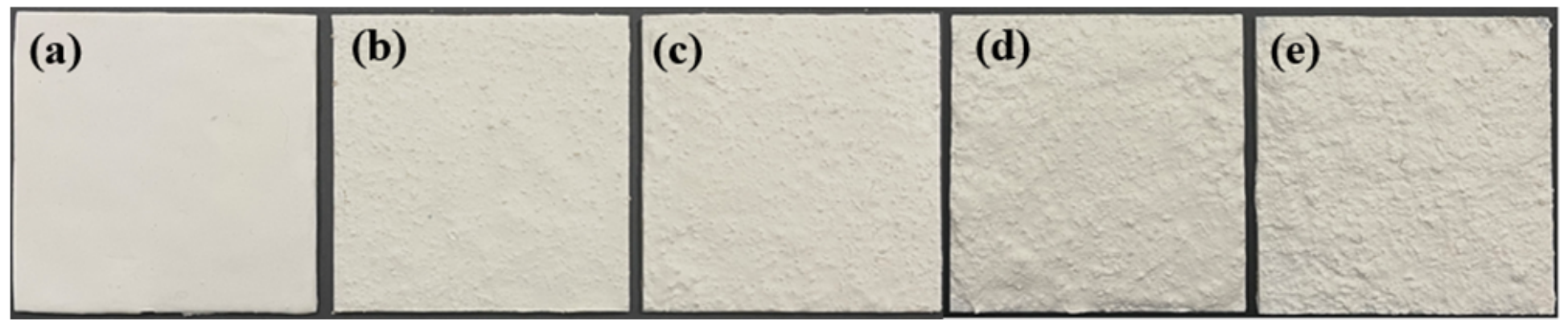

Figure 4

The images of samples before the fire protection test (a) SP-0, (b) SP-1, (c) SP-2, (d) SP-3, (e) SP-4
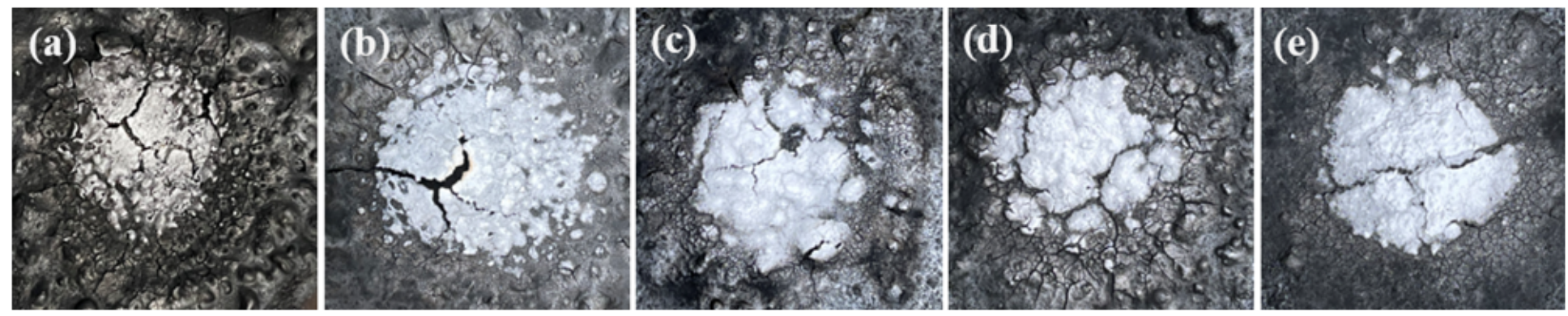

Figure 5

The images of char layers after the fire protection test (a) SP-0, (b) SP-1, (c) SP-2, (d) SP-3, (e) SP-4

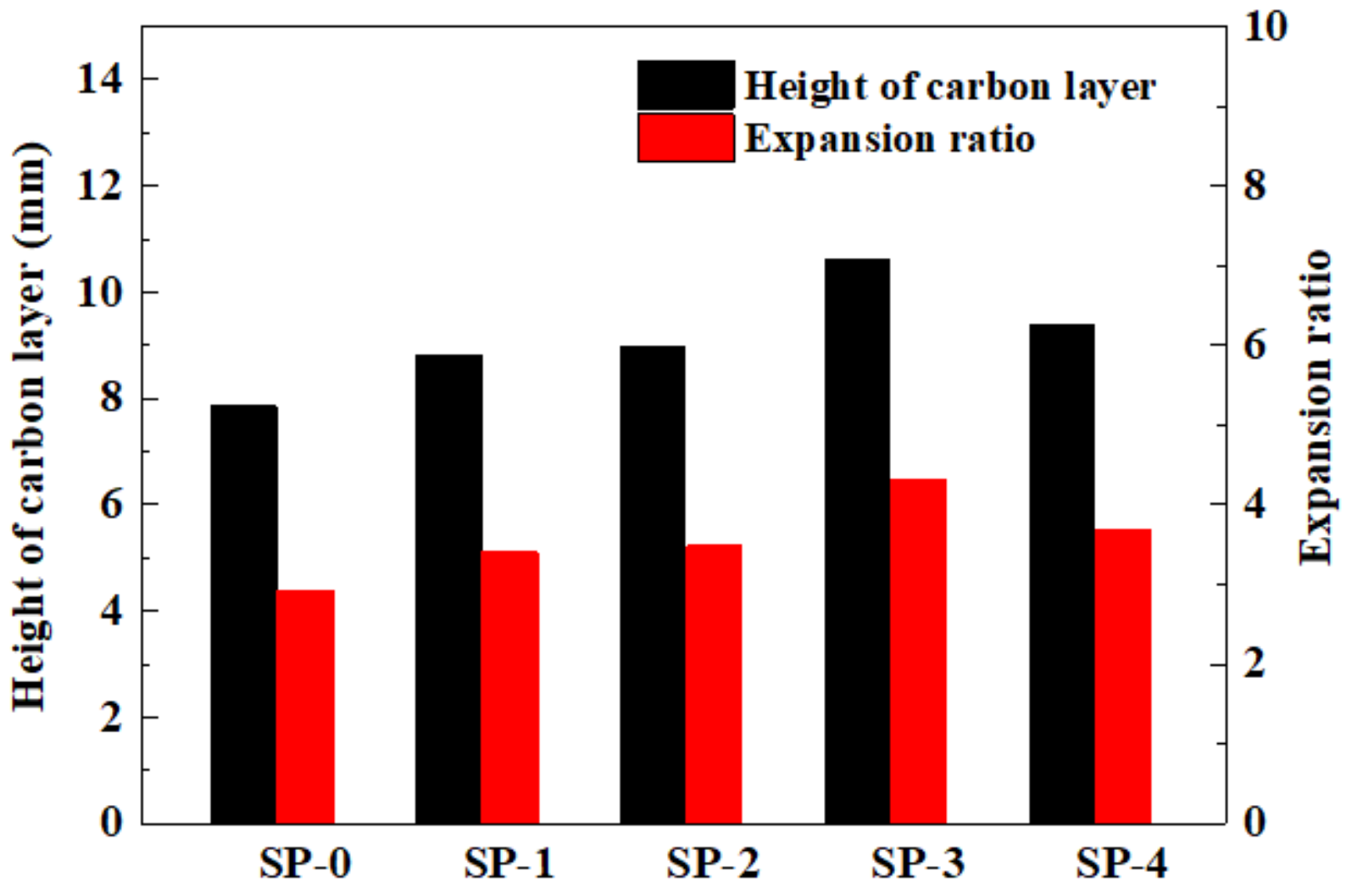

Figure 6 
The height and expansion rate of char layer

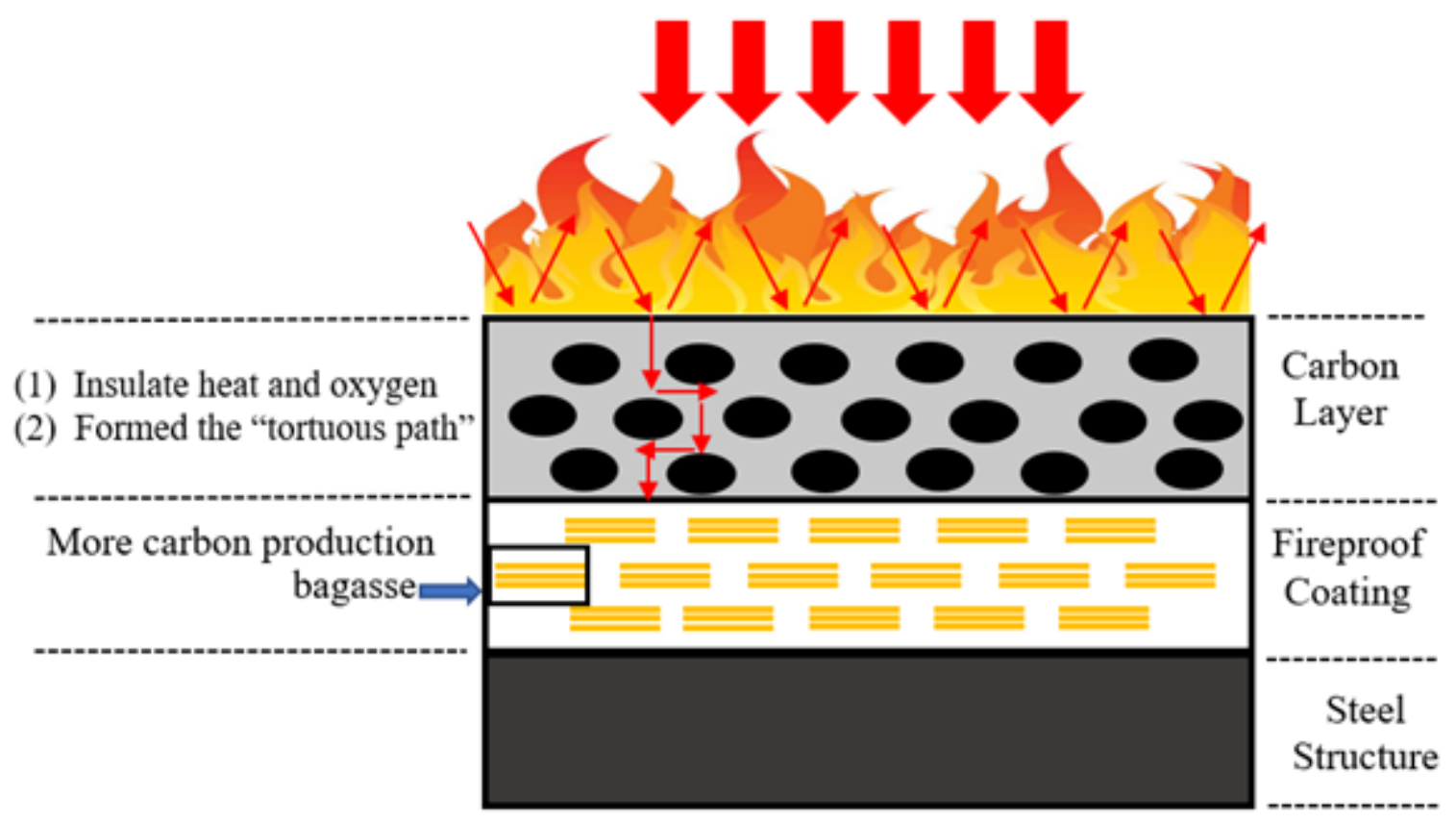

Figure 7

Flame-retardant mechanism of the fireproof coating filled with bagasse

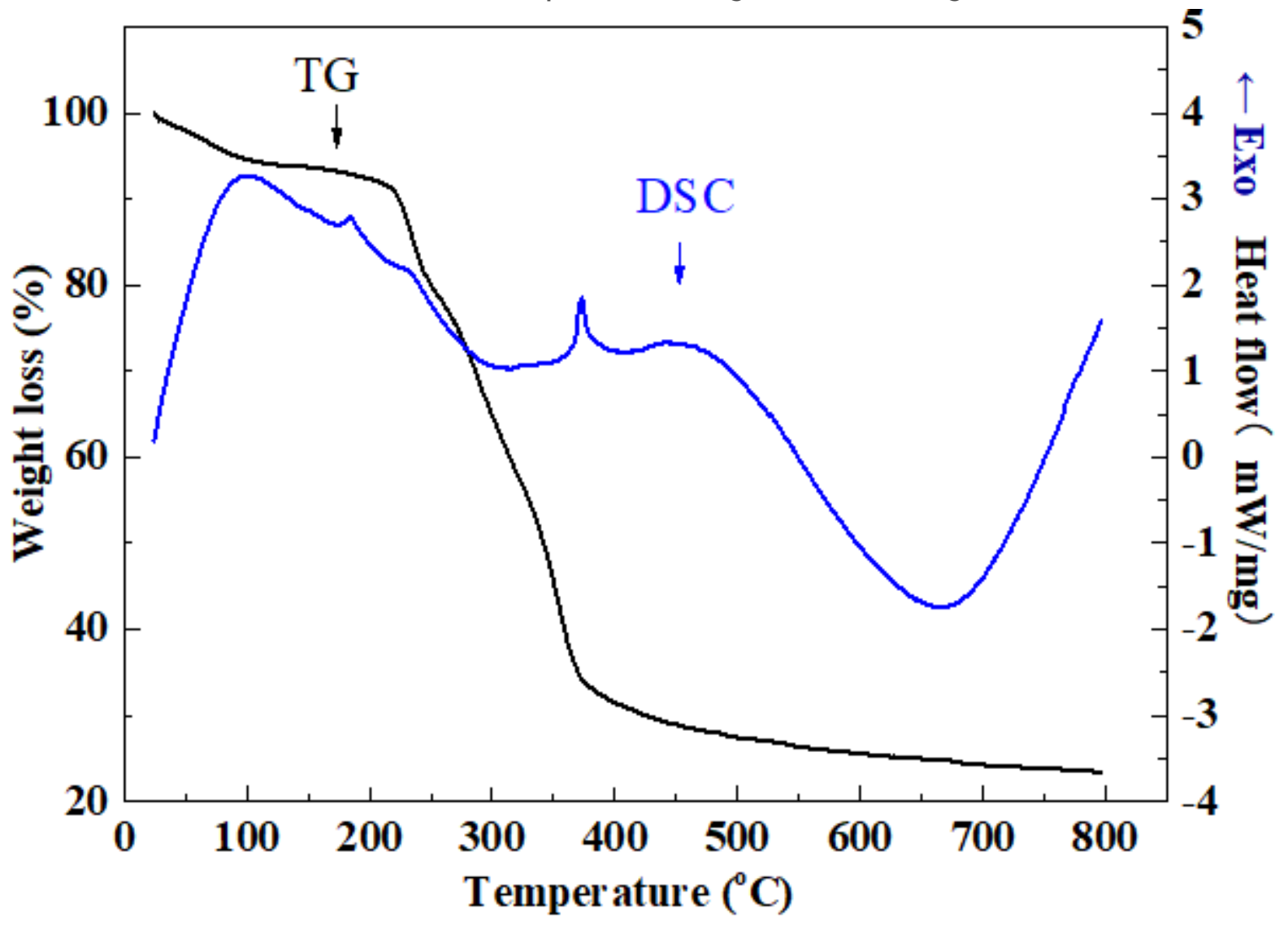

Figure 8 
The TG/DSC curves of bagasse

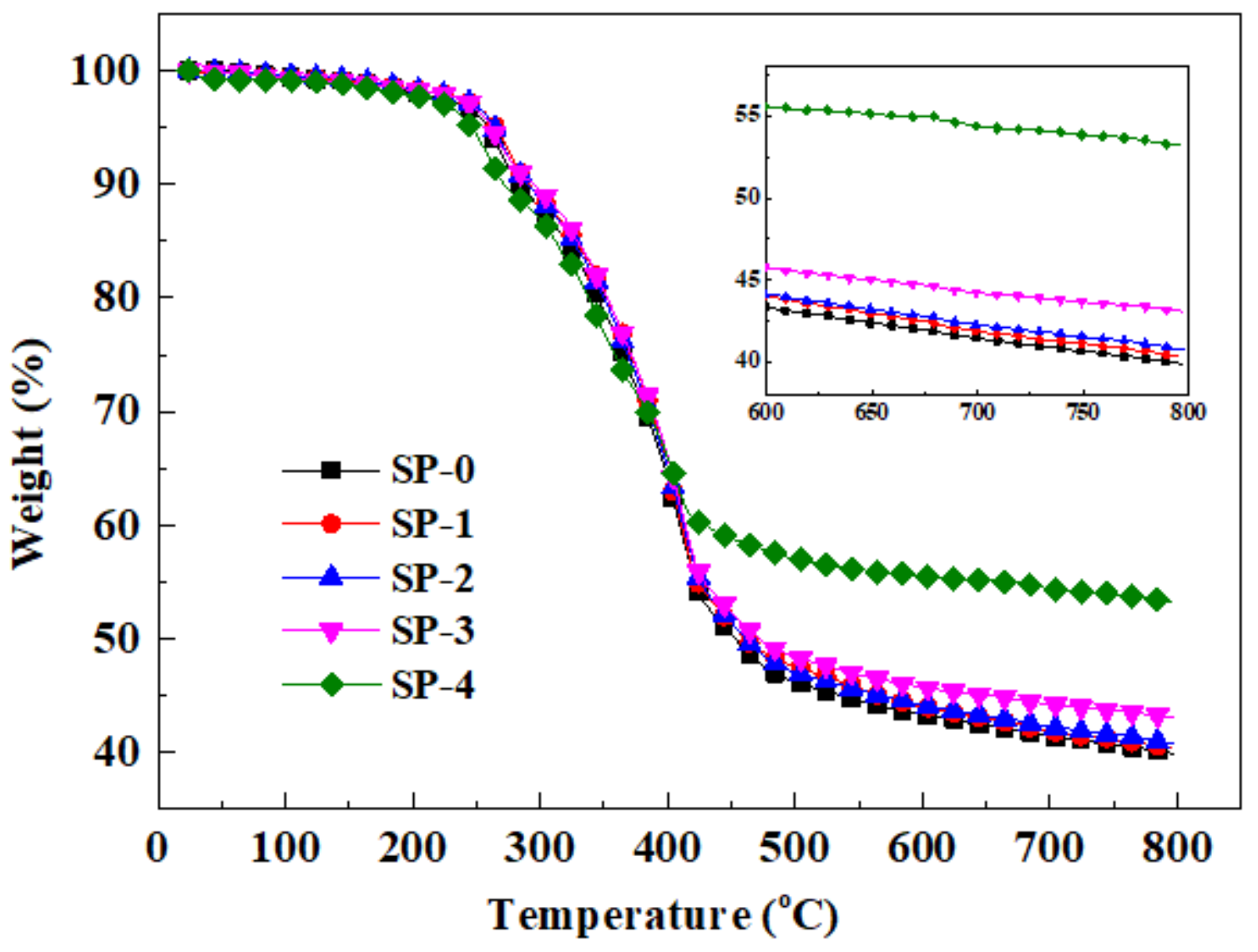

Figure 9

The TG curves of fireproof coatings
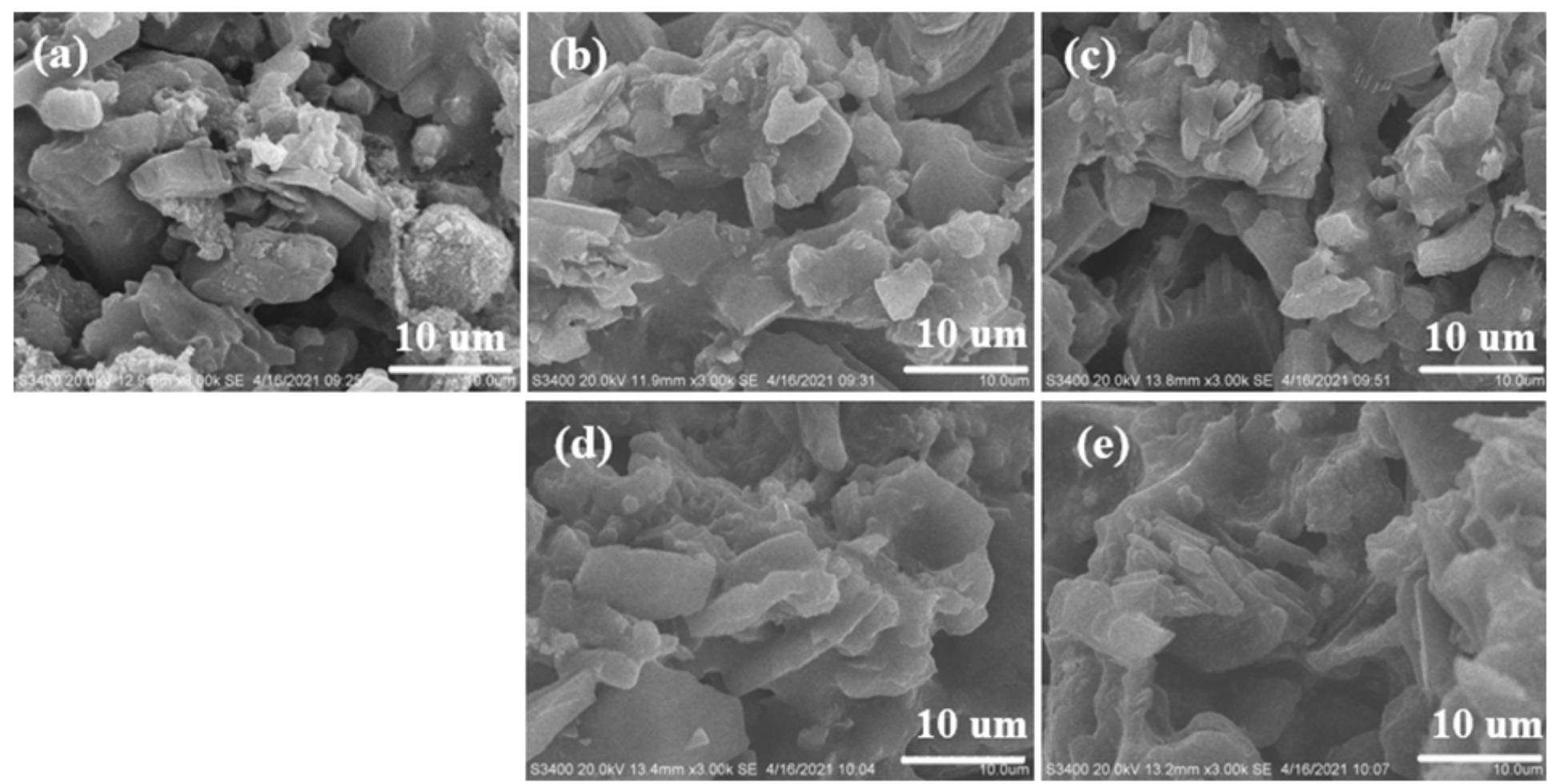
Figure 10

The SEM images of cross section of fireproof coatings (a) SP-0, (b) SP-1, (c) SP-2, (d) SP-3, (e) SP-4
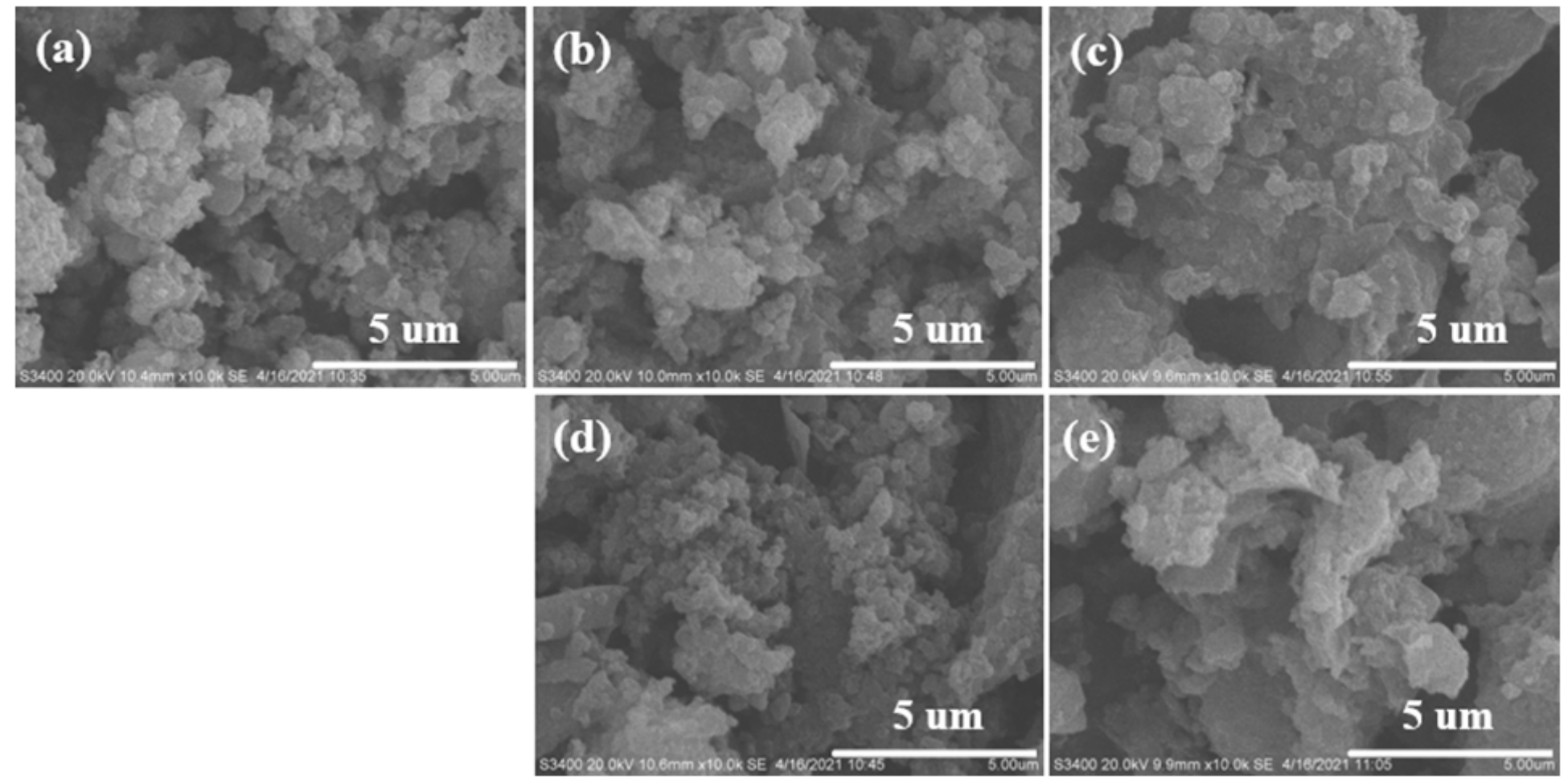

Figure 11

The SEM images of char layer after fire protection test (a) SP-0, (b) SP-1, (c) SP-2, (d) SP-3, (e) SP-4 


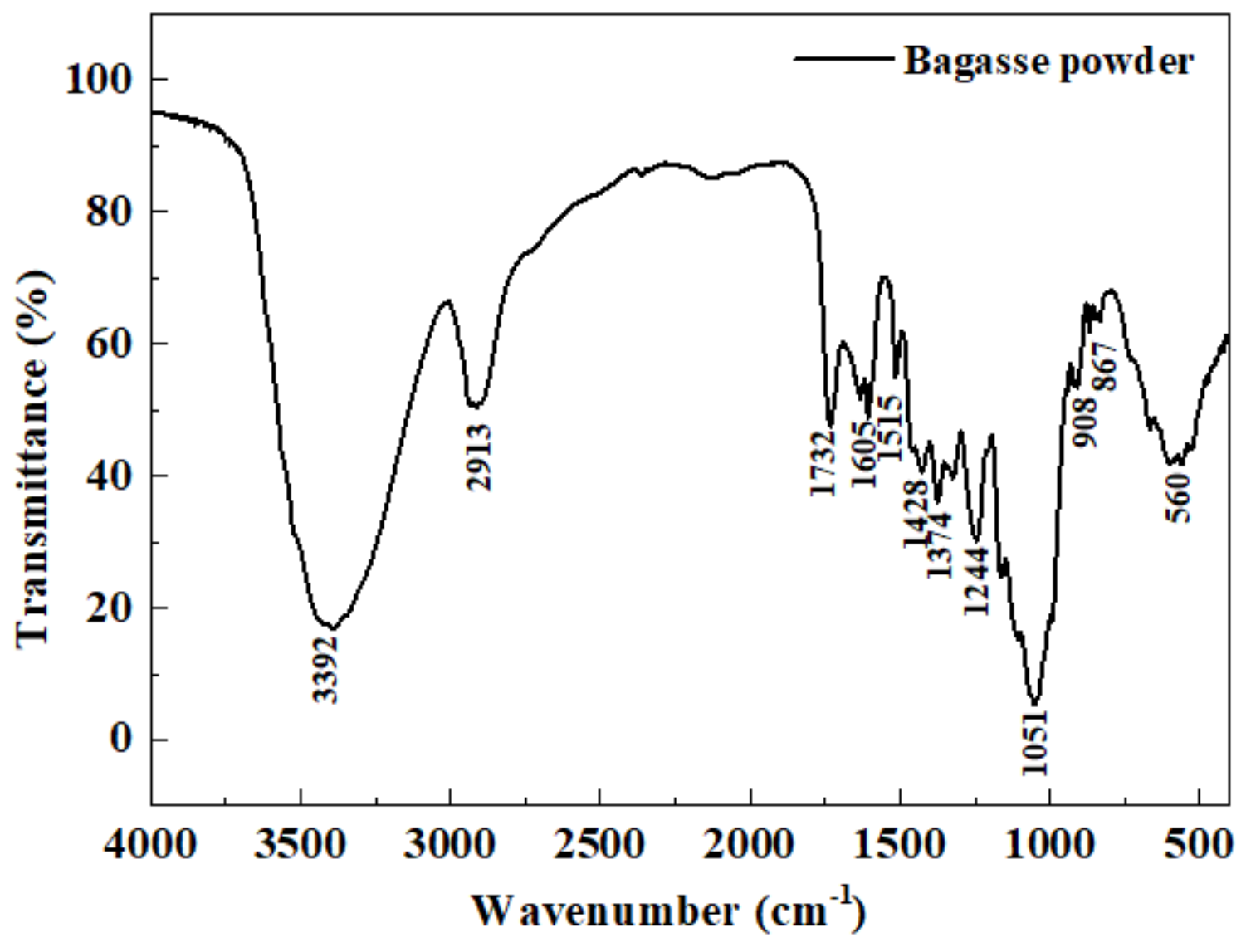

Figure 12

The FTIR of the bagasse 


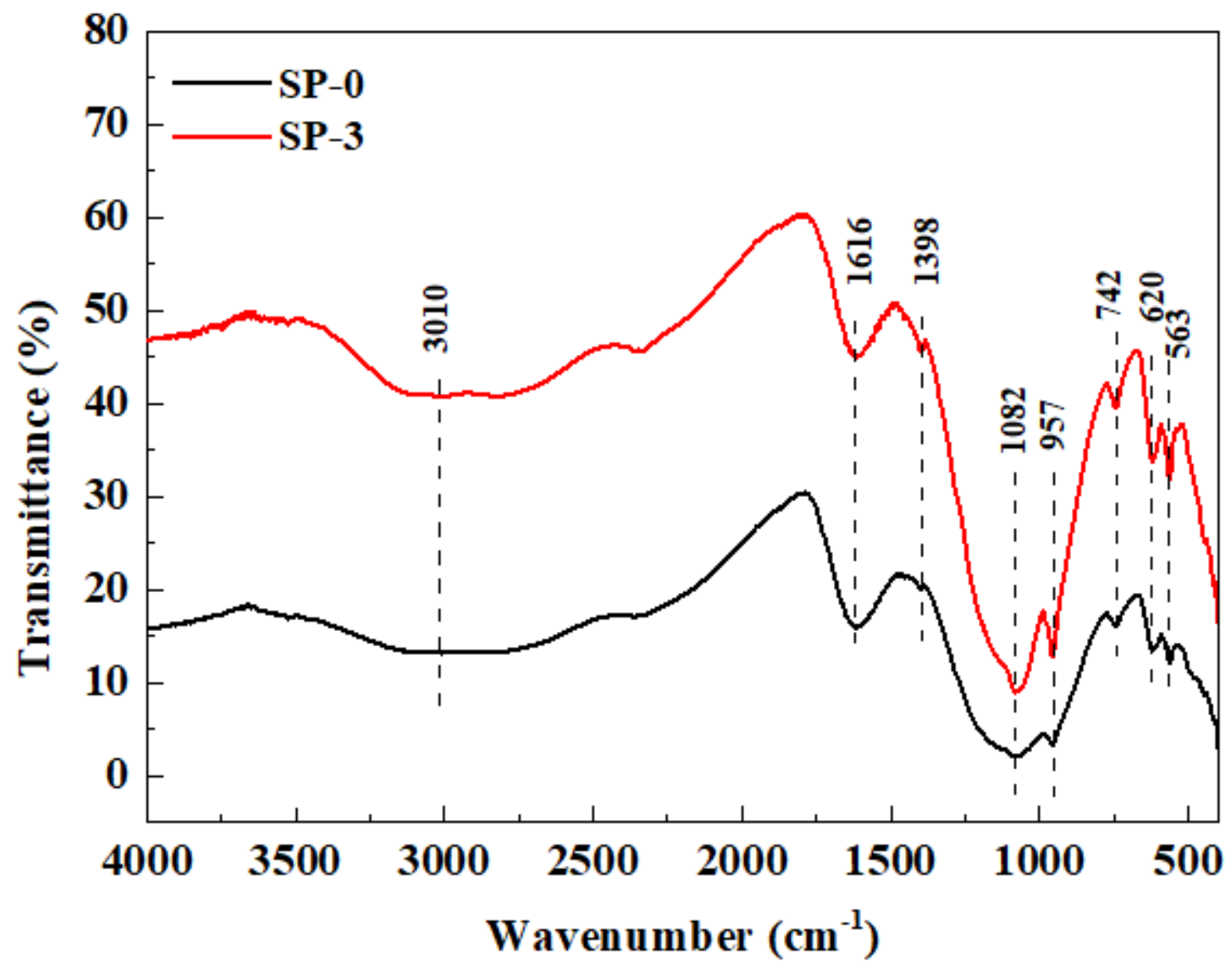

Figure 13

The FTIR of the fireproof coatings 


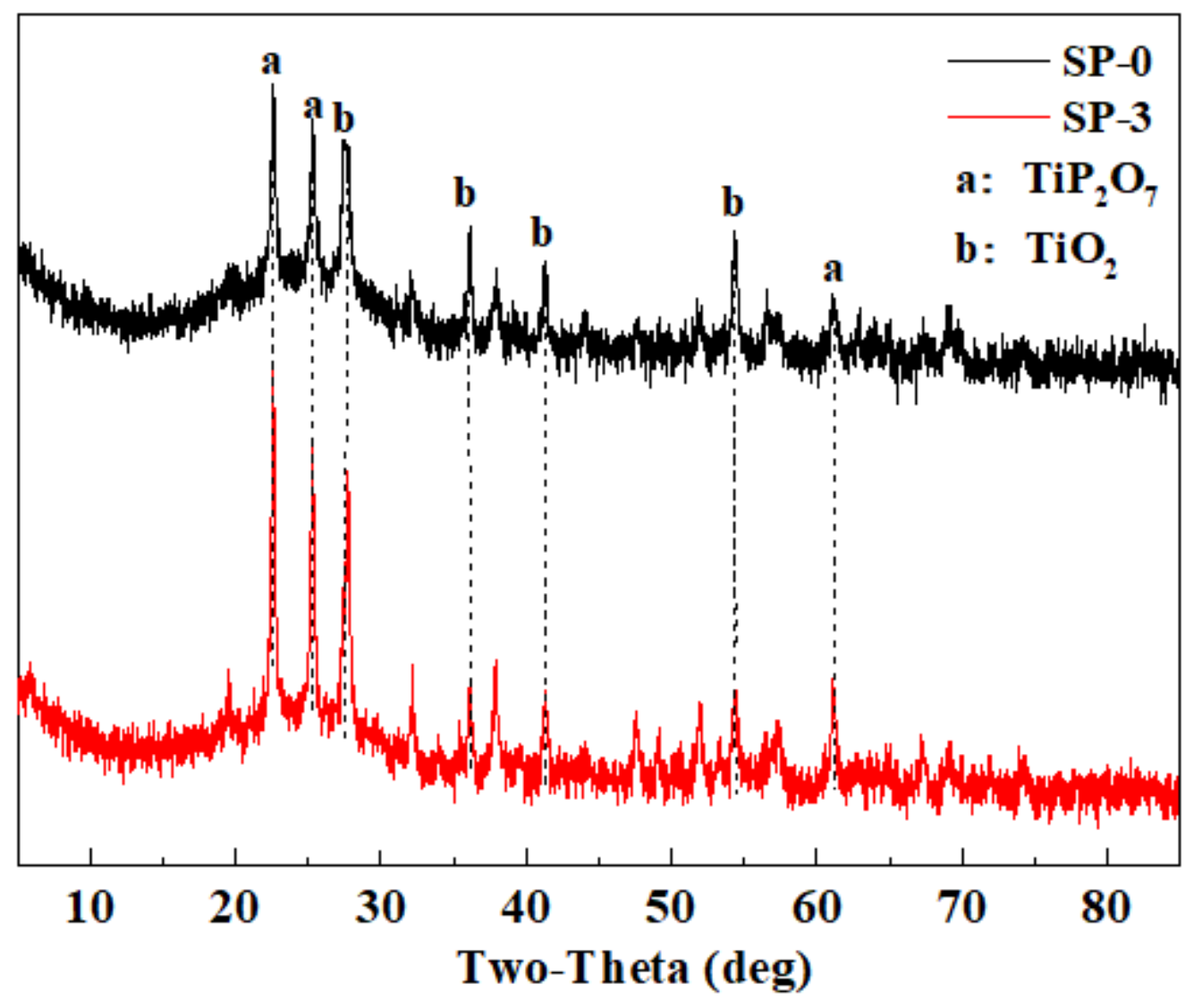

Figure 14

The XRD of the char layers
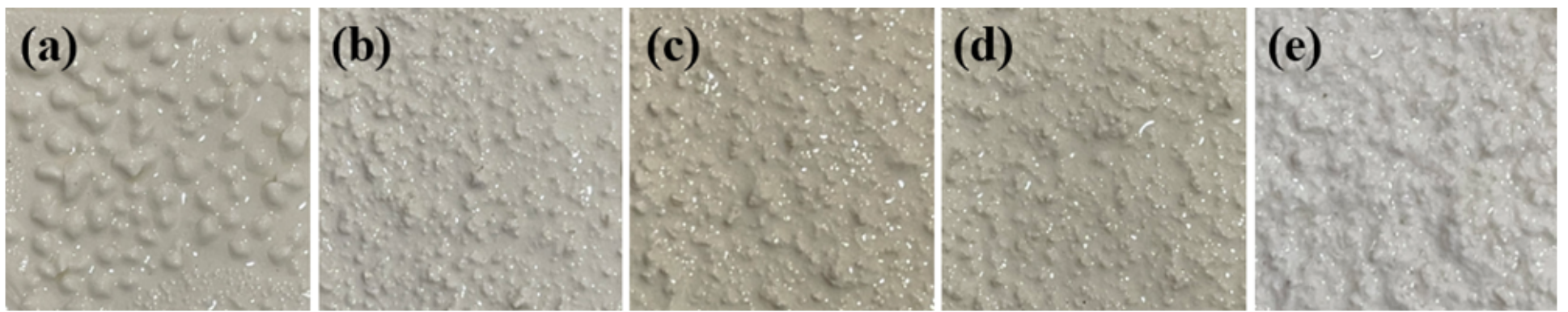

Figure 15

The images of the fireproof coating immersed for $1 \mathrm{~h}$ (a) SP-0, (b) SP-1, (c) SP-2, (d) SP-3, (e) SP-4 


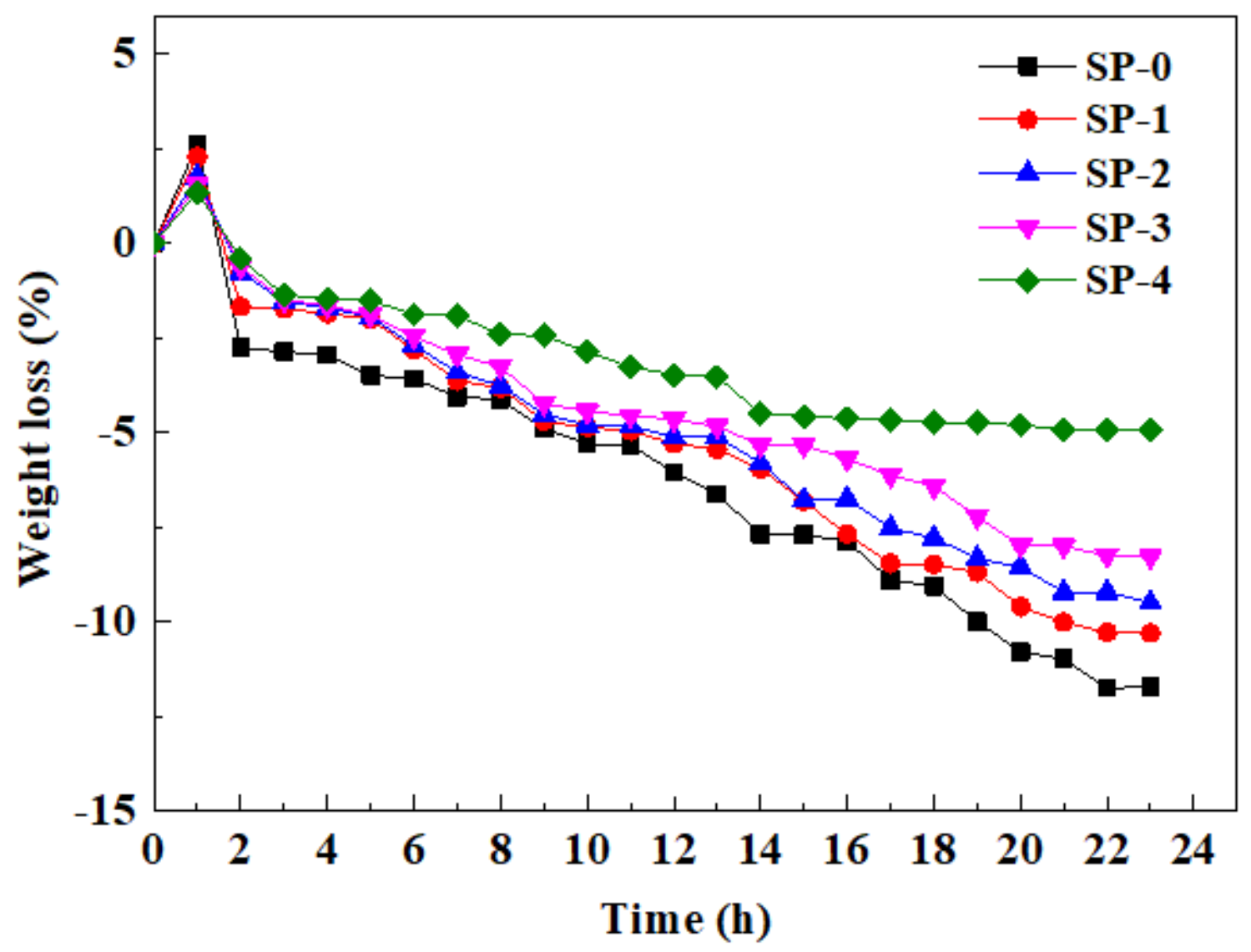

Figure 16

The weight change of the coatings immersed in distilled water
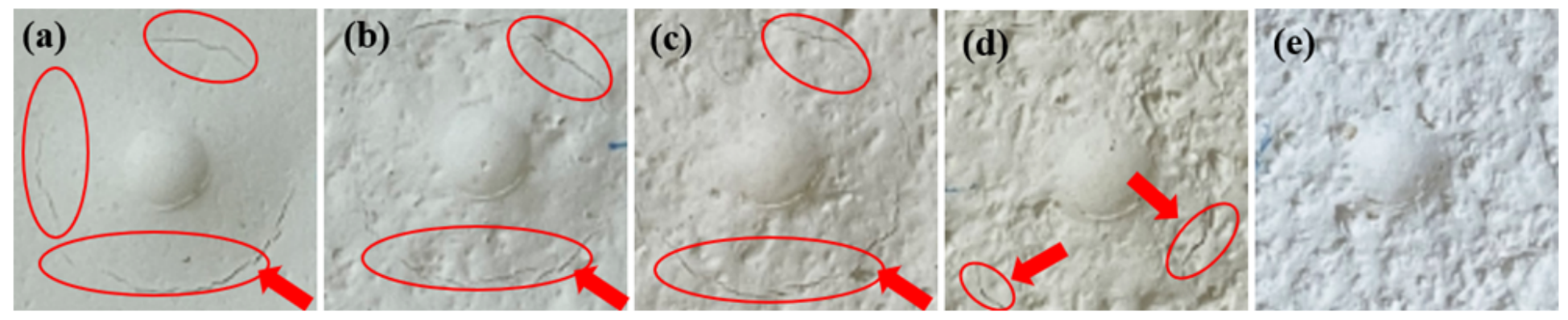

Figure 17

The images of the fireproof coating after the mechanical properties test (a) SP-0, (b) SP-1, (c) SP-2, (d) SP-3, (e) SP-4 